\title{
Bertolt Brecht e a (auto)formação musical por meio das Peças didáticas
}

\author{
JOSÉ NORONHA \\ STEPHAN A. BAUMGÄRTEL
}

\begin{abstract}
José Renato Noronha (Zé Renato Mangaio) é ator, diretor, músico e professor do Curso de Licenciatura em Teatro da Universidade Federal de Santa Maria (UFSM). Doutorando em pelo Programa de Pós-graduação em Educação (PPGE) da UFSM. Desenvolve a pesquisa de (Auto)formação com Musicais produzindo experiências formativas que resultaram nas encenações de Diz que sim de Bertolt Brecht, com o Coletivo Baal e de Os Saltimbancos de Sérgio Bardotti e Luiz Bacalov com versão de Chico Buarque e Pipa de Telma de Oliveira Ferreira com o grupo FAPEM- UFSM. Além de atuar em espetáculos musicais tais: Quem Tem Medo de Curupira? de Zeca Baleiro e Pavão Misterioso do grupo Viracena.
\end{abstract}

Stephan A. Baumgärtel é professor associado da Universidade do Estado de Santa Catarina na área de história do teatro, estética teatral e dramaturgia. É idealizador e coordenador do projeto Encontro com Dramaturgo da UDESC que convida regularmente dramaturgos brasileiros a dar palestras e administrar oficinas. Enquanto pesquisador, investiga principalmente as modalidades de poéticas políticas teatrais na contemporaneidade e modalidades não-miméticas de encenar textos teatrais não-dramáticas. Leciona principalmente nos seguintes campos: dramaturgia contemporânea, teatro pós-dramático e performativo, análise da encenação teatral. Bolsista de Produtividade em Pesquisa do CNPq Nivel 2. 
- RESUMO

A partir de uma análise do papel da música no contexto de criação das Peças didáticas de Bertolt Brecht, sobretudo em relação ao texto dramático, o presente artigo elabora uma reflexão sobre a concepção brechtiana a cerca da relação destes elementos. Considera-se o contexto em que essas obras foram desenvolvidas e seus propósitos (auto)formativos em que o próprio Brecht é autor/proponente e sujeito do experimento que realiza em colaboração com outros artistas e com os participantes. Resulta disto uma consciência sobre as possibilidades e os desafios de sua própria práxis. A proposta brechtiana em relação à música foi tomada como referência para um processo (auto)formativo de "remusicalização" do texto: Der Jasager na montagem do espetáculo Diz que sim do Coletivo Baal de Florianópolis-SC.

\section{PALAVRAS-CAVE}

Música, teatro, musical, peças didáticas, formação.

\section{- ABSTRACT}

Starting with an analysis of the function of music in the creation of Bertolt Brecht's Learning plays, especially what concerns the written text, this paper reflects on Brecht's understanding of the relation that these elements engage in. The article takes into account the historical contexts of their creation as well as Brecht's (self)educational proposals in which he was simultaneously author, proponent and inserted subject of an experiment that he realized as a collaborative process with other artists and participants. As a result of this process arises a consciousness of the possibilities and challenges present in his own praxis. The brechtian proposal concerning the music was taken as a reference to the author's (self)educational process of a "remusicalisation" of the play Der Jasager, brought on stage as Diz que sim by the Coletivo Baal from Florianópolis - SC.

\section{KEYWORDS}

Music, theater, musical, learning plays, formation. 


\section{Introdução}

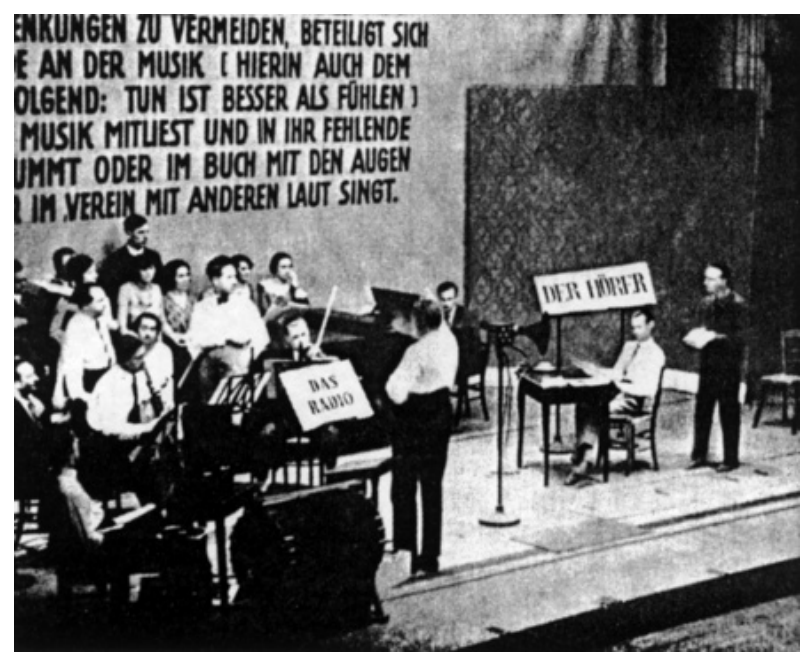

Figura 1. Lindberghflug, 19291 - Orquestra original da rádio e o ouvinte (com legenda nos cartazes) e aparentemente Brecht à direita.

Fonte: Mediakunstnetz. ${ }^{2}$

A aprendizagem que conhecemos da escola, da preparação profissional, etc., é indubitavelmente penosa. Mas deve ter-se em conta em que circunstâncias e para que objetivo ela se processa. Trata-se, na realidade, de uma compra. A instrução é mera mercadoria, adquirida com objetivo de revenda. Em todos aqueles que ultrapassaram a idade escolar a instrução tem de ser levada a efeito quase em sigilo, pois quem confessa ter de aprender, coloca-se simultaneamente, num plano inferior, considerando-se alguém que sabe pouco. Além disso, o proveito da instrução encontra-se muito limitado por fatores que estão fora do alcance da vontade do estudante. (BRECHT, 2005, p.49)

Fosse tocando clarinete nas apresentações do cômico Karl Valentin ${ }^{3}$, violão para acompanhar seus poemas nas parcerias com os músicos Franz S. Bruinier e Kurt Weill ou fazendo óperas com música de Paul Dessau, a produção artística de Bertolt Brecht sempre foi permeada de música (Figura 1): "Toda a obra de Brecht está associada à música. No levantamento feito por Kowalke, apenas uma de suas aproximadamente cinquenta obras dramáticas completas não possui música" (TEIXEIRA JÚNIOR, 2014 p.25). Sua própria prática foi se desenvolvendo junto aos seus parceiros, segundo Anatol Rosenfeld:

\footnotetext{
1 Orquestra original da rádio legendada pelo cartaz: "Das Radio" à direita da foto e à esquerda o ouvinte: "Der Hürer". No momento desta foto a obra ainda se chamava "Lindberghflug", em menção a Charles Lindbergh que foi posteriormente excluída. Parece ser Bertolt Brecht em pé, à direita, na foto. A gravação do áudio da obra está acessível no mesmo site.

2 Disponível em:< http://www.medienkunstnetz.de/works/bertold-brecht/audio/1/>. Acesso em: 3 de maio de 2017 às 6:30.

${ }^{3}$ Segundo Teixeira Júnior, Brecht aparece em uma foto tocando clarineta em 1920 em um cabaré da Oktoberfestshow em Munique, junto de Karl Valentin e LiesI Karlstadt (TEIXEIRA JÚNIOR, 2014 p.24).
} 
Boa parte do êxito da Ópera dos três vinténs decorre sem dúvida da música de Weill. Contudo, a própria esposa do compositor, Lotte Lenya (a famosa intérprete de Jenny), reconheceu que Weill muitas vezes seguiu as ideias de Brecht longamente discutidas e muitas vezes ilustradas na guitarra pelo dramaturgo. Brecht exerceu forte influência sobre todos os seus compositores. Sugeriu-lhes que os songs, ao invés de apoiar, deveriam interromper a ação e nunca dificultar o entendimento do texto. Exige que os atores separem nitidamente os níveis da fala comum, da fala intensa e do canto: "Nada é mais detestável do que o ator se dando o ar de quem não percebe, ao começar a cantar, que acaba de abandonar o terreno da fala comum". (ROSENFELD, 2012, pp.124-125).

O que importa no contexto desse artigo é a relação funcional entre a música e a elaboração de experiências, por parte de artistas e espectadores, como outras formas de aprendizado que não as escolares. A presença da música adquire neste processo uma função bem precisa dentro daquilo que podemos chamar de "intenção formativa" de suas obras, especialmente no objetivo de formar um "novo público" para ópera e teatro, treinado em uma nova "arte de olhar"4. Benjamin nos fornece uma perspectiva sobre essa proposta brechtiana que, em seu ideal, concebe um processo de aprendizagem interativo e dissolve o conceito tradicional de obra e de espectador bem como o da comunicação entre eles no intuito de garantir seu impacto didático-formativo:

A tarefa maior da direção épica é exprimir a relação existente entre a ação representada e a ação que se dá no ato mesmo de representar. Se todo o programa pedagógico do marxismo é determinado pela dialética entre $o$ ato de ensinar e o de aprender, algo análogo transparece, no teatro épico, no confronto constante entre a ação teatral, mostrada, e o comportamento teatral que mostra essa ação. O mandamento mais rigoroso desse teatro é que "quem mostra" - o ator como tal - deve ser mostrado. (BENJAMIN, 1987, p.88)

Em meio a uma produção considerável de obras de teatro musical chamounos atenção a ênfase e o vínculo do caráter musical com a questão pedagógica das Peças didáticas. A coletânea de textos de Bertolt Brecht publicada em Teatro Dialético chega mesmo a nomeá-las: "Cantatas didáticas" (BRECHT, 1967, p. 88). A tese de Geraldo Martins Teixeira Júnior: Dramaturgia, gestus e música - Estudos sobre a colaboração de Bertolt Brecht, Kurt Weill e Hanns Eisler, entre 1927 e 1932 (2014) fornece um aprofundamento nessa característica significativa de grande parte das obras de Brecht recorrendo, sobretudo, a estudos publicados em língua estrangeira e na área da musicologia. Vejamos um excerto que apresenta bem a confluência de várias referências, em que destacam-se ainda em sua tese Kenneth Ray Fowler, Kim Kowalke, Michael Morley e Joy Calico:

\footnotetext{
$\overline{4}$ Brecht usa o termo "Zuschaukunst", que junto com uma nova arte de atuação deve propiciar condições favoráveis para que a prática artística possa contribuir à maior de todas as artes, a arte de viver. Ver BRECHT, Bertolt. Gesammelte Schriften, vol. 3. Frankfurt: Suhrkamp, p. 191.
} 
Em 1918, ele escreve sua primeira peça Ball ${ }^{5}[\mathrm{sic}]$, que incluía várias canções para violão que Brecht, como Wedekind, ajustava as melodias à sua própria maneira e tinha por hábito cantar, ele mesmo" (WILLET, 1964, p.4) Brecht trabalhou inicialmente com Franz S. Bruinier, entre 1925 e 1927, quando Bruinier tanto compunha canções a partir de poemas de Brecht quanto escrevia as partituras de canções compostas por Brecht (HENNENBERG, 1990, p.1-44). O grande songbook de Brecht (Das große Brecht-Liederbuch), publicado pela Suhrkamp Verlag, lista 121 canções e partituras, sendo as primeiras 19 de autoria de Brecht". (TEIXEIRA JÚNIOR, 2014, pp.24-25)

A autora Joy Calico em seu livro Brecht at the opera (2008) afirma que a música chegou mesmo a ser "subestimada na literatura brechtiana" (Idem, p.18) ${ }^{6}$, o que se deveu em parte por um processo de "desmusicalização"(Idem) desenvolvido até nos próprios textos teóricos de Brecht. Sabemos que Brecht não manteve as partituras das versões originais para as Peças didáticas (Idem, p.19) com exceção em A Decisão. Por um lado, isso pode revelar um propósito de assumir a independência das linguagens e a abertura a outro processo criativo com o texto, mais flexível a uma recriação sem a moldura determinante da música. Pois, se a música, por um lado, como diz Calico: "é essencial para a sua realização porque estabelece uma ordem, a qual de outra maneira seria perdida neste tipo de estrutura e ainda facilita a experiência coletiva dos participantes" 7 (Idem, p.18); por outro, se estabelece uma forma. Para um processo de aprendizagem coletiva e experimental isto limitaria as variáveis possíveis do experimento. Mas, não seria essa limitação a intenção pedagógica a ser aprendida? Não teria essa música a intenção de fixar um Gestus preciso estabelecido pelos autores? Ou o próprio texto e a música estariam sujeitos a alterações de significados de acordo com as montagens?

$\mathrm{Na}$ sequência de nossas reflexões sobre o contexto teórico e da produção das Peças didáticas, faremos algumas considerações a cerca de aspectos da investigação realizada com o experimento de recriação musical, ou seja, uma "remusicalização" do texto Der Jasager (1930), para o espetáculo Diz que sim do Coletivo Baal de Florianópolis-SC.

\section{A música nas Peças didáticas}

As Peças didáticas mostram Brecht ampliando sua consciência das possibilidades de usar a música em favor da comunicação de suas ideias, sempre dialogando com seus interlocutores-músicos. O recurso da música popular já lhe era presente e suas referências vinham especialmente da música dos cabarés alemães (Songs), das operetas (Singspiel) e agora encontrava reforços da Nova música alemã (Neue Musik) que introduzia o dodecafonismo rompendo com um padrão da música ocidental.

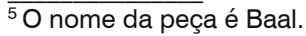

${ }^{6}$ Conforme original: The music is traditionally underestimated in Brechtian literature, thanks in no smallpart to the playwright's own efforts to "demusicalize" the genre in later theoretical texts. (CALICO, 2008, p.18)

${ }^{7}$ (...) and music is essential to its realization because it imposes order on an otherwise loosely structured genre and facilitates the collective experience of the participants. (Idem) 
Esses elementos se fundiram no processo das obras musicais do período, especialmente em suas óperas e peças didáticas, e adquiririam intenções formativas para seus projetos estéticos à época vinculando-se a proposta marxista. No final dos anos 20 e início dos anos 30, Brecht - sob influência de seu contato com as análises sociais marxistas - passou por um processo de transformação artística. As $\mathrm{Pe}$ ças didáticas são fruto de sua despedida de modelos musicais mais tradicionais e do engajamento com as proposições marxistas, como nos diz Benjamin em seu texto $O$ que é o Teatro épico?:

A tarefa maior da direção épica é exprimir a relação existente entre a ação representada e a ação que se dá no ato mesmo de representar. Se todo o programa pedagógico do marxismo é determinado pela dialética entre $o$ ato de ensinar e o de aprender, algo análogo transparece, no teatro épico, no confronto constante entre a ação teatral, mostrada, e o comportamento teatral que mostra essa ação. O mandamento mais rigoroso desse teatro é que "quem mostra" - o ator como tal - deve ser mostrado (BENJAMIN, 1987, p.88).

Ao que Luciano Gatti comenta:

Como reconhece Benjamin, "esse esforço crônico de Brecht em legitimar a arte em face do entendimento termina sempre por leva-lo à parábola". Essa preocupação é extremamente forte numa época em que Brecht estava particularmente preocupado com o alcance didático de seu trabalho e procurava, por meio de considerações de âmbito filosófico-científico, incorporar o problema da luta de classes à sua produção. Nas palavras de Benjamin, tratava-se de "mobilizar a autoridade do marxismo para si" a partir do próprio teor dogmático e teórico da poesia didática (GATTI, 2008, p.54).

Esse processo impactou sobre o uso da música e as parcerias com diferentes compositores como Kurt Weill, Paul Hindemith e finalmente Hans Eisler, com quem realizou Die Maßnahme (A decisão). Com essa parceria, Brecht consolidou seu alinhamento às propostas marxistas em que Eisler já estava profundamente engajado. Eisler participara do coletivo de Agitprop: Rotes Sprachrohr (Megafone Vermelho), e cujas propostas e experiências traziam semelhanças reconhecidas com as Peças didáticas ${ }^{8}$.

Podemos perceber a proposta da formação do público e do artista em relação ao contexto que se lhe apresentava, sobretudo, nas reflexões de Brecht e seus colaboradores principalmente acerca da forma que se realizariam as Peças didáticas $^{9}$, como experimentos que foram adquirindo especificidades e revisões. Mas foi nelas, muito mais que nas famosas Peças épicas, que Brecht desenvolveu sua ideia de um teatro colaborativo que provoca em seus participantes um processo de aprendizagem, e portanto, de autoformação. Diz ele, por ocasião da criação de $A$ peça didática de Baden-Baden sobre o acordo:

\footnotetext{
${ }^{8}$ Para mais informações sugerimos: KOUDELA, 1991 (pp.8-9)

${ }^{9}$ Ver o livro de Reiner Steinweg, Das Lehrstück. Brechts Theorie einer politisch-ästhetischen Erziehung, de 1976. Ele serviu a Ingrid Koudela como base de sua pesquisa. Citamos, quando nos parece oportuno, diretamente do livro alemão.
} 
A "peça didática", configurada por algumas teorias de cunho musical, dramático e político, que visam uma atividade artística coletiva, foi feita para um processo de autocompreensão [Selbstverständigung] de seus autores e de todos que participam dela ativamente. Não foi feita para ser uma vivência [Erlebnis] para qualquer tipo de gente. Nem é totalmente acabada. O público, na medida em que não ajuda ativamente no experimento, não desempenharia o papel de receptor, mas de alguém que está simplesmente presente. (Programa Deutsche Kammermusik Baden-Baden 1929, in Steinweg, 1976, p. 11-12) ${ }^{10}$.

Aquele que está simplesmente presente é mais testemunha que espectador tradicional. Ele não se identifica com a situação e com os personagens apresentados, mas os observa, possivelmente a partir de atitudes e interesses investigativos diferentes. O que transforma, em última análise, a proposta Brechtiana em um grande laboratório de (auto)formação de seus participantes, são os procedimentos para incentivar que todos possam participar dele ativamente com essa atitude investigativa, como o autor declarou na citação anterior. Essa finalidade fez com que se buscasse superar a separação entre artistas (atores e músicos) e espectadores, e desenvolvesse os experimentos com esses que seriam seu público. O compositor Paul Hindemith que junto com Weill compôs a partitura para essa peça, anotou:

A peça não visa seu uso para apresentações teatrais ou musicais nas quais alguns poucos divertem ou edificam uma multidão por suas produções. O público participa da apresentação como uma pessoa ativa: canta as frases que na partitura são atribuídas à "multidão". Alguns "indivíduos" dessa multidão que de antemão estudaram as referidas partes sob a direção de um regente ou de um cantor as apresentam cantando para a multidão. Essa, por sua vez, as repete depois. [...] É possível que essa interseção de solos, coro e multidão não se dá de maneira a satisfazer imediatamente os participantes. Mas nesse tipo de exercício artístico não importa uma apresentação sequencial fluida dos números individuais. Por isso, é preferível que ao invés de simplesmente apresentá-los, seja usado um verdadeiro processo de estudá-los (STEINWEG, 1976, p.12) ${ }^{11}$.

Mas o que importa então se não é uma apresentação sem problemas e atritos? Certamente não apenas uma hibridização dos participantes, compostos agora por artistas qualificados e operários leigos que supera a distinção entre atuantes e não-atuantes.

\footnotetext{
${ }^{10}$ Conforme original: Das Lehrstück, gegeben durch einige Theorien musikalischer, dramatischer und politischer Art, die auf eine kollektive Kunstübung hinzielen, ist zur Selbstverständigung der Autoren und derjenigen, die sich dabei tätig beteiligen, gemacht und nicht dazu, irgendwelchen Leuten ein Erlebnis zu sein. Es ist nicht einaml ganz fertig gemacht. Das Publikum würde also, sofern es nicht bei dem Experiment mithilft, nicht die Rolle des Empfangenden, sondern eines schlicht Anwesenden spielen

${ }_{11}$ Conforme original: Das Stück ist nicht zur Verwendung in Theater- und Konzertaufführungen gedacht, bei der einige durch ihre Produktionen eine Menge belustigen oder erbauen. Das Publikum ist als handelnde Person an der Aufführung beteiligt: es singt die in der Partitur der "Menge" zugewiesenen Sätze. "Einzelne" aus der Menge, die vorher die betreffenden Stellen einstudiert hatten, singe diese unter der Leitung eines Dirigente (oder Vorsängers) erst der Menge vor. Diese wiederholt sodann. [...] Es ist denkbar, daß das Ineinandergreifen von Soli, Chor und Menge nicht gleich zur zufriedenheit der Beteiligten ausfällt. Bei dieser Art gemeinsamer Kunstübung kann es auf ein reibungsloses Abspielen der einzelnen Nummern gar nicht ankommen. Darum ist ein richtiges Einstudieren einem bloßen Durch- und Vorspielen vorzuziehen
} 
Essa é uma consequência formal de um princípio mais profundo que era a necessidade de incitar todos a realizar uma atividade investigativa e crítica acerca do material temático apresentado bem como do papel dos participantes (eles mesmos) dentro dele. Esse papel diz respeito, sobretudo, à dimensão social. É ela que apresenta o fio condutor direcional e o limite das atitudes investigativas. Isso fica patente na seguinte anotação de Brecht em seus Escritos sobre o teatro:

Eu utilizava novos princípios de construção para cada obra e modificava também a maneira de interpretação dos atores. Trabalhávamos com alunos e com atores em escolas e com alunos em teatros. TrabaIhávamos (nas peças didáticas) sem plateia; os atuantes atuavam para si mesmos. Formávamos ensembles com operários, que nunca haviam pisado num palco e artistas altamente qualificados, e diante de toda diversidade de estilos, nenhum elemento da plateia podia contestar a unidade do que era apresentado (...) O único princípio que nunca ferimos foi o de submeter todos os princípios à tarefa social, que tínhamos por objetivo cumprir em toda obra. (KOUDELA, 1991, p.9).

Todos os experimentos formais com a atuação, com o papel do espectador e com a interrelação das linguagens cênicas são pensados para servir a essa finalidade. É ela que não só possibilita como até exige a reconfiguração da relação atorespectador, mas também das relações entre as diferentes linguagens artísticas em cena.

\section{Percurso (auto)formativo da música para as Peças didáticas}

La pieza didáctica está destinada em cualquier caso tanto a los actores como a los espectadores. La pieza didática se diferencia esencialmente como caso especial porque la peculiar pobreza de la tramoya simplifica y acerca el intercambio del público con los actores, de los actores com el público. Cada espectador podrá también llegar a actuar. Y de hecho resulta más fácil representar al "maestro" que al "héroe". En la primera version de El vuelo de los Lindebergh, que se publicó em uma revista ilustrada, el aviador figuraba todavia como héroe. Dicha version estava destinada a su glorificación. La segunda version surge - lo cual es muy instructivo - gracias a uma corrección de Brecht. !Que regocijo no recorrió ambos continentes em los días que siguieron a este vuelo! Pero el regocijo Dio um estallido y se quedo en sensacionalismo. Brecht se esfuerza en El vuelo de los Lindbergh por descomponer el espectro de la "vivencia" para conseguir de el los colores de la "experiencia". Esa experiencia que solo podia sacarse del trabajo de los Lindbergh y no de la excitación del público, y que además debía devolverse a "los Lindbergh". (BENJAMIN, 1987a, p. 38).

Benjamin (1987a) na segunda versão publicada em 1939 do texto O que é 
o Teatro épico?, em versão aqui apresentada em espanhol ${ }^{12}$, destaca que o foco concentrado da dramaturgia em uma trama simples com um único foco temático a ser abordado, como por exemplo: o acordo (Einverständnis), permitia um melhor intercâmbio entre atores e público e vice-versa. Como vimos, no capítulo anterior, na citação de Paul Hindemith, a princípio, pouco importaria se viesse a ser levado ou não à público para ser assistido por outras pessoas que não os participantes da experiência. Também para Kurt Weill, como veremos na epígrafe do capítulo IV, havia um aprendizado a ser adquirido pelos participantes, ou o que Brecht chamou de uma autocompreensão (Selbstverständigung). Esta experiência importava mais a esses participantes ativos, que realmente estivessem implicados no projeto de (auto)conhecimento, do que a uma plateia de expectadores passivos. As apresentações para uma plateia não eram excluídas da experiência, mas ao cantar junto com o coro, propõe-se um novo grau de implicação com a proposta. Decorre daí um acompanhar ativamente da trama, pois se contracenará com a situação proposta e se experimentará um posicionamento na interpretação do texto.

Benjamin (1987, 1987 a) percebe que as questões que mobilizaram Brecht no estabelecimento dessas propostas foram norteadas pela intenção de permitir a apropriação da vivência artística como experiência social. Um tipo de apropriação por partes, que permite uma contextualização do fenômeno a partir de diversos ângulos, possibilitando assim que a vivência se torne de fato uma experiência consciente. Nesse contexto, a música é veículo para estabelecer um ou mais ângulos. Destrinchar o fenômeno cênico implica em seguir esses ângulos e estabelecer uma compreensão tática que prepara para um posicionamento social. Nesse sentido, Brecht (KOUDELA, 1991 pp.13-14) apresenta sua perspectiva de uma Grande pedagogia, em que a separação entre palco e plateia (por mais ativa que esta seja) é superada e o público uma força participativa no sentido de ser um coprodutor da ação cênica. Por isso, ela condiciona a música e seu uso. A música precisa ser artística e ao mesmo tempo acessível aos participantes-figurantes. E o espaço de seu uso não pode mais ser um espaço especificamente marcado, como o fosso cênico. As Peças didáticas foram realizadas para contrapor-se aos esquemas de produção do sistema: com amadores, em espaços que não as salas de espetáculo, o processo dialético e de aprendizagem era mais valorizado do que o resultado.

Em certo sentido, a práxis possibilitada pelas Peças didáticas foi para Brecht repleta da "autoconsciência" (STEINWEG, 1976, pp.11-12) necessária em seu contexto de produção. Sua experimentação se tornou processo e dispositivo (pedagógico) de conhecimento e para o conhecimento (didática) num momento crítico para a República de Weimar, que ante a profunda crise econômica agravada pela queda da Bolsa de Nova lorque assistia à ascensão do nazismo. A proposta de certa forma permitia a multiplicação das experiências, atendia a grandes grupos, popularizava um recurso de produção e seu modelo chegou mesmo a ser copia$\mathrm{do}^{13}$.

\footnotetext{
12 Trata-se da segunda versão do Texto escrito por Walter Benjamin em 1939. Cuja versão utilizada foi publicado pela editora Taurus sob o título: ¿Que és el Teatro Epico? - Segunda version (BENJAMIN, 1987 a).

${ }^{13}$ No original: "By 1931 these journals could report a good-sized repertoire of Lehrstücke and related pieces, much of it written by people outside Brecht's immediate circle." (CALICO, 2008 p.18).
} 
Foi uma reação contundente aos mecanismos da produção mercantil e industrial, que permeavam e ainda permeiam a produção artística, e que com a música tradicional da época tinham potencializados os seus efeitos narcotizantes, e que procurava despertar outras consciências. A referência ao uso narcótico dos produtos da indústria do entretenimento aparece em alguns textos de Brecht vejamos o que escreveu em $O$ uso da música no Teatro épico:

Ouvi algumas composições interessantes de Hindemith e sobretudo de Eisler. Este escreveu música para filmes convencionais, e música extremamente séria. Mas os filmes sonoros, um dos ramos mais prósperos do comércio internacional de entorpecentes, dificilmente desenvolverão por muito tempo essas experiências (BRECHT, 1967 p.88).

A proposta pedagógica da Grande Pedagogia das Peças didáticas encontrou espaço e condições para se desenvolver nos Festivais de música, em coros escolares e grandes coros e teatros de proletários que se revelaram como alternativa de produção, estratégia, escolha e coincidência de propósitos especialmente diante da crise econômica e da ascensão do nazismo. Sua primeira experiência com esse direcionamento, mais perto ainda daquilo que Brecht chamava a Pequena Pedagogia das peças épicas com sua separação de artistas e espectadores como produtores do espetáculo, havia sido a Cantata Mahagonny (Mahagonny Songspiel), apresentada em 1927 no Festival de Música de Câmara de Baden Baden, para o que Kurt Weill aceitou escrever novas melodias para cerca de "meia dúzia de songs já existentes" Brecht diz a respeito:

Até aquela época, Weill tinha escrito uma música relativamente complicada, de caráter psicológico. Quando aceitou musicar uma série de songs com letras mais ou menos banais, estava rompendo corajosamente com um preconceito obstinado de muitos compositores modernos. O sucesso dessa tentativa de aplicar a música moderna à song foi muito significativo. Qual era a novidade dessa música, senão o modo não habitual de utilizá-la? (BRECHT, 1967 p. 83).

As óperas Ópera de Três Vinténs de 1928, e na sequência: Ascensão e queda da cidade de Mahagonny composta entre 1929 e1930, já traziam inovações estéticas na relação da música com a cena que estabeleceriam princípios utilizados no Teatro épico como um todo. Gestus musicais e estranhamento revelavam na atitude gestual de quem cantava contraposições com a melodia e a letra, que possibilitando interpretações críticas. Brecht registrou aspectos de seu processo nos Cadernos de tentativas (Versuche) e expôs muitas vezes sua reflexão acerca das experiências, por exemplo, reafirmando a natureza operística de Mahagonny escreve: "Procuramos transformar um instrumento de alegria num instrumento pedagógico e certas instituições de divertimento em organismos de difusão" (BRECHT, 1967, p.65).

Os recursos utilizados na Ópera de três vinténs foram diversos e já apontavam os principais elementos da teoria do teatro épico: "Para o canto mais do que para qualquer outra coisa, é importante que aquele que mostra seja também mostrado" (Idem, p.73), no texto sobre a Música-Gestus: "O que é mais importante é o fato de que o princípio de procurar o Gestus pode dar-Ihe condições de adotar sua própria atitude política quando fizer música. Para isso é essencial que ele estabeleça 
um Gestus social" (Ibidem, p.78). Esse Gestus social não é em primeiro lugar um gesto politicamente correto, mas um gesto oriundo de uma colaboração e de uma interação do artista com seu entorno social e sobretudo popular:

Uma consideração a mais a ser tomada na composição de música com um sentido mais facilmente compreensível é a de que não se trata de uma questão de boa vontade, mas acima de tudo de competência e estudo - e o estudo só pode ser desenvolvido em contato com as massas e com outros artistas, não no isolamento.

Com esse Gestus musical como Gestus social, Brecht propunha-se a estabelecer um "novo contrato" de recepção, como aponta Joy Calico (2008, p.17):

As Peças didáticas e Ópera possuem finalidades diametralmente opostas no continuum de experiências no teatro musical. Brecht observou que o contrato social estabelecido com o público de ópera não somente favorece e empatia do público com os personagens, mas suspende a descrença, e submete a manipulação emocional, que é feita sob profunda influência de um poderoso narcótico que é a música contínua. Brecht contestou isto de duas maneiras, uma partindo dentro do sistema, com suas duas óperas: Ópera de três vinténs e Ascensão e queda da cidade de Mahagonny; e outra partindo de fora do sistema, com suas quatro peças didáticas (Vôo sobre o oceano, A peça didática de Baden-Baden sobre o acordo, Aquele que diz sim e a Decisão), que dispensaram qualquer público. As Peças didáticas puderam efetivamente tornar os presentes um não-público transformando-os em participantes, ou ao menos, em prováveis participantes. Brecht trabalhou simultaneamente em ambos os gêneros de teatro musical no final dos anos de 1920 gerando a teoria do teatro épico e determinando seu primeiro marco: a renegociação com o pacto da audiência com o teatro, e por extensão, do contrato social dos cidadãos com a sociedade. O fato que o Teatro épico comprovadamente é também musical, como emergiu de um simultâneo engajamento com dois gêneros diametralmente opostos de teatro musical, Peças didáticas e opera, justifica mais investigação. ${ }^{14}$ (CALICO, 2008, p.16[tradução nossa]

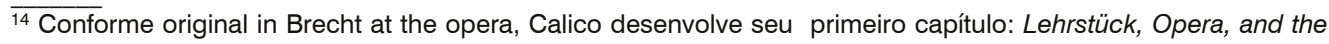
New Audience Contract of the Epic Theater a partir do parágrafo da seguinte maneira: "Lehrstücke (learning plays) and opera occupy opposite ends of the continuum for audience experience in musical theater. Brecht observed that the social contract in effect for opera audiences stipulated not only that participants empathize with characters, suspend disbelief, and submit to emotional manipulation, but that they do so under the influence of the powerful narcotic of continuous music. Similar conditions were imposed in nonoperatic theater, but opera was the most extreme example because of its perpetual, manipulative musical presence. Brecht countered this in two ways: from within the system, in his two operas (Threepenny Opera and The Rise and Fall of the City of Mahagonny), and from outside the system, in his four Lehrstücke (Lindbergh Flight, Lehrstück, He Who Said Yes, and The Decision), which did not require an audience at all. Lehrstücke could effectively render attendees a nonaudience by transforming them into participants or, at the very least, prospective participants. Brecht's simultaneous work in both genres in the late 1920s generated the theory of epic theater and determined its primary goal: renegotiation of the audience's pact with the theater and, by extension, the citizen's contract with society. The fact that epic theater's provenance is also musical, as it emerged from his simultaneous engagement with two diametrically opposed musical theater genres, Lehrstück and opera, warrants further inquiry.
} 


\title{
Alternativa de produção
}

Weill (apud CALICO, 2008) nos aponta um caminho de experiência "cuidadosamente calculada" para ser realizada pelos participantes que podem aprender mais do que sentir "alegria no fazer musical":

\begin{abstract}
A música para uma ópera didática precisa sem dúvida ser calculada para permitir um estudo cuidadoso e até demorado. Pois o valor prático da ópera didática consiste precisamente no estudo, e no que diz respeito aos performers, a apresentação desse tipo de obra é menos importante que o treino relacionado a ele. Inicialmente, esse treinamento é puramente musical, mas poderia ser no mínimo igualmente intelectual. ...Merece absolutamente todo esforço, portanto, ver que uma peça didática oferece aos estudantes a oportunidade de aprender alguma coisa além da alegria no fazer musical. (Ênfases no original) (Weill apud CALICO, 2008 p.19) ${ }^{15}$ [tradução nossa]
\end{abstract}

Trata-se, portanto, de uma proposta que deve ser também envolvente para os participantes. Esses não precisavam ser especialistas, mas podiam ser de comunidades, sindicatos ou escolas. Ensaiando a obra, eles a conhecerão por dentro e realizarão sobre ela sua prática, que permite seu estudo juntamente com os profissionais envolvidos no processo de construção e de criação da peça - sobretudo com as orientações para a interpretação, que era conduzida pelo próprio Brecht. Brecht vislumbrava com esses "novos atores" a possibilidade de um processo formativo diferenciado, na práxis fundamentada pela dialética marxista, na qual estava mergulhado à época. O teor experimental e dialético destes processos o fez, por exemplo, reescrever Der Jasager como Der Neinsager (Aquele que diz não), considerando a reação dos participantes e dos críticos. O interesse formativo, ou do resultado do processo chegaria mesmo a ser avaliado no caso de A Decisão, escrita com a música de Hans Eisler, ao final da premiére foram distribuídos questionários sobre a apresentação. Ou seja, um processo formativo, reflexivo que quis se avaliar, mensurar as reações, compreender a recepção da experiência que quer avaliar e aprender com seus resultados. Uma recepção cujo foco não era a questão de uma excelência musical. Ou talvez melhor, processos de criação e recepção musical nos quais a própria música foi pensada e proposta como comentário sociocultural e político sobre os temas apresentados nas peças.

\footnotetext{
$\overline{{ }^{15} T h e}$ music of didactic opera must absolutely be calculated for careful, even lengthy study. For the practical value of didactic opera consists precisely in the study, and as far as the performers are concerned, the performance of such a work is far less important than the training that is linked to it. At first this training is purely musical, but it should be at least as much intellectual. ...It is absolutely worth every effort, therefore, to see that a didactic piece offers the students the opportunity of learning something in addition to the joy of making music (Emphasis in original) (Weill apud CALICO, 2008, p.19)
} 


\section{A Experiência/Tentativa "Diz que Sim":(Auto)formação musical dos artistas em cena para o espetáculo}

Todas: O mais importante de tudo

É aprender a estar de acordo

O mais importante de tudo

É aprender a estar de acordo

(Naipe 2 abrindo a segunda voz)

O mais importante de tudo

É aprender a estar de acordo

O mais importante de tudo

É aprender a estar de acordo

Naipe 1: Muitos dizem que sim

Naipe 2: mas sem estar de acordo

Naipe 1: Muitos não são consultados

Naipe 2: E outros...

Naipe 1: Estão de acordo com o erro

Naipe 2: Por isso... (Da capo al Fine)

(Fine)

Recriar a música da Peça didática: Der Jasager, considerando a proposta formativa que a mobilizou, foi uma das tarefas desenvolvidas na experiência de remusicalização do espetáculo Diz que sim. O propósito era originalmente conceber uma prática musical que atendesse as necessidades do grupo de participantes para realizar a encenação do texto que originalmente fora concebido como o libreto de uma Ópera escolar (Schuloper) cuja melodia acompanhava os versos em alemão sem perder a potência musical como recurso gestual.

Teve-se a possibilidade de recriar a música a partir da versão em português, remusicalizando o texto de Brecht procurando estabelecer um processo colaborativo entre músicos e as participantes: atrizes da montagem, que ao final seriam proponentes da nova gestualidade musical recriada. As atrizes, muitas das quais alunas do programa de pós-graduação da UDESC, já haviam desenvolvido a experiência de encenação de Baden-Baden resultado de um processo formativo das atrizes na graduação. Através da Peça didática de Baden-Baden sobre o acordo, portanto, já conheciam os procedimentos da peça didática, mas o aspecto musical como uma forma de potencializar a interpretação com Gestus e estranhamentos ainda não havia sido experimentado pelo grupo. A escolha de inserir novamente a música no texto pedia uma compreensão da direção musical sobre os aspectos da proposta da música em cena no universo do trabalho com as Peças didáticas.

No contexto de produção, as dificuldades para a realização da música era minimizada pela vivência em canto coral trazida por três das seis participantes, e de das atrizes cujo pai é músico e que tocava um pouco de violão o que ajudou nas compreensões obtidas no processo. Ou seja, as intenções interpretativas procuraram ser traduzidas na dinâmica musical, na melodia, na harmonia, no arranjo a partir daquilo que as atrizes esboçavam em frases melódicas que surgiam em exercícios propostos pela direção musical. Contou-se depois de um tempo com a 
colaboração de um músico ${ }^{16}$ que acompanhou o processo para (Auto)formação da música em cena para o espetáculo Diz que sim. Nesse processo pretendeu-se compreender as possibilidades da música como Gestus, capaz de comunicar através da gestualidade, e de estranhamento, capaz de produzir uma observação crítica do espectador diante do inusitado, através das intérpretes a partir do texto brechtiano em relação a um novo contexto de produção. Nesse sentido, este capítulo pretende responder a seguinte pergunta: Como as intérpretes num processo (auto)formativo se apropriaram da música para estabelecer um discurso cênico a partir do texto Brechtiano e, também, em relação a própria posição de Brecht em relação ao texto?

Na medida em que a música para a cena dessa montagem se tornava assimilada, permitia-se a utilização consciente da mesma para a produção de Gestus e de estranhamentos por parte das intérpretes. Muitas vezes, o texto e seus personagens receberam críticas similares às apresentadas pelos críticos e participantes da versão original, especialmente relativas ao caráter de submissão ao autossacrifício, ao heroísmo do personagem Menino, vinculado a uma moral religiosa; por outro lado, surgiram novas questões em relação aos personagens Professor e Estudantes, que revelaram relações de poder criticadas com Gestus e estranhamentos tanto pela cena quanto pela música: ridicularizando o comportamento "beato" de um coro de Estudantes cegos pela devoção a um Professor que, por sua vez por outra, manifestava sua a vaidade exibindo ornatos desnecessários num canto afetado em sua postura e potência.

Portanto, no processo, a elaboração de um discurso consciente, que utilizasse a linguagem da música em cena deveria estar de acordo com uma encenação que também revelasse sua posição crítica. Desta forma o processo seguiu coerente com a proposta formativa e estética brechtiana das Peças didáticas, mas, para poder utilizar-se da música, esta estaria condicionada a um domínio técnico que dependeria da condução do formador, para que nas experimentações as atrizes pudessem exercitar a liberdade criativa. Soluções simples foram sendo propostas no intuito de que o gesto musical e o gesto cênico confluíssem para um gesto social mais significativo. Os participantes estavam conscientes da necessidade de direcionar a intenção de produzir de Gestus e estranhamentos (Verfrendungseffekt) na reflexão sobre a temática da aquiescência, do estar de acordo, apresentada pelo texto e de revelar suas contradições abrindo-se a dialética.

Aprendizagem musical e aprendizagem temática potencializaram-se mutuamente. Na medida em que emergiu uma consciência mais objetiva desses elementos no processo de criação das atrizes, as práticas de criação musical favoreceram sua fixação na interpretação das atrizes que já conheciam as intenções da proposta nas experiências. Entretanto, o resultado do processo não produziria uma formação, uma experiência, para o receptor que viesse apenas assistir a cena - seu processo formativo é outro e que depende também de seu grau de implicação e interesse na experiência e no conhecimento produzidos.

Os Gestus produzidos pelos participantes visavam comunicar as possíveis contradições das atitudes dos personagens em cena reveladoras das circunstâncias socialmente criadas. Alguns princípios da Peça didática como a colaboração da

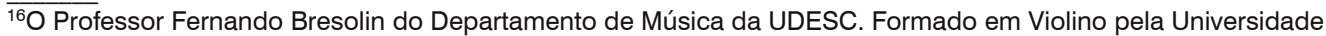
Federal de Santa Maria e que propôs além de arranjos com o violino e piano, temas musicais que foram improvisados e geraram a construção das músicas finais da peça.
} 
música com a gestualidade da cena, o processo colaborativo, a discussão sobre os resultados cênicos e sua possível recriação, foram reconstruídos para conseguir estabelecer um processo formativo direcionado para que a música também tivesse seu caráter significativo enfatizado.

O estudo de melodias que seriam compostas deveria considerar sua execução em cena, com frases melódicas relativamente simples sem grandes intervalos e que pudessem provocar ao público à reflexão sobre o que estava sendo apresentado pelo texto cantado através de seu andamento, suas quebras determinadas por pausas prolongadas e ênfases estabelecidas em certos pontos da dinâmica. Ainda que a música propusesse alguma moldura, o resultado interpretativo abria-se a crítica ao que estava sendo visto, não para estabelecer uma forma definitiva na sua interpretação ou um ponto final de uma indagação temática e musical, mas possibilitando a reflexão crítica - sujeita a reconstrução no processo de ensaios e apresentações.

A música original de Kurt Weill foi descartada por não haver interlocução possível com a proposta do grupo em relação ao gênero musical da Ópera, ou mesmo a estrutura de produção necessária. A proposta composta em processo da direção e das atrizes visou um público cujo acesso não vincula seu interesse à formação para a linguagem operística. O processo resultou na elaboração de composição e de arranjos musicais originais e populares. A realização incluiu a divisão das vozes e dois músicos para tocarem: acordeom, violino, violão e piano além de outro violão tocado por uma das atrizes e de alguns músicos e instrumentos disponíveis: 6 garrafas, 2 violões, 1 balde como percussão, acordeom, violino e piano. Toda a harmonização dos elementos foi conquistada no processo mediante trabaIho e exercícios técnicos.

O texto de Diz que sim respondia ao desejo do grupo, Coletivo Baal, de continuar os estudos com as peças didáticas. Diante do sucesso da experiência anterior com o espetáculo Baden-Baden, o grupo pretendia considerar a experiência com Diz que sim, em relação a uma vivência tida nas Cordilheiras dos Andes na Bolívia. No percurso das experiências foram sendo definidas novas diretrizes e possibilidades de realização do projeto - somente Diz que sim foi produzida ao longo do ano de 2016, com encontros semanais regulares, em que a principal questão foi elaborar e executar a música em cena considerando que seria um processo consciente do sentido que esta música estaria adquirindo para a experiência - do ponto de vista estético, mas também como uma reflexão sobre o processo social de criação coletiva diante da temática brechtiana do Acordo (Einverständnis). Essa prática, como aprendizagem musical e de outras questões inerentes a temática, não poderia ser levadas a público sem o treinamento do trabalho musical assumido pelas atrizes que não estariam apresentando a mostra de um processo mas o resultado final da criação de um espetáculo. Por sua vez, o espetáculo foi resultado de seu aprendizado no processo de criação que permitiu que se empoderassem de suas vozes para produzir o canto, e de sua musicalidade para produzir música e do seu discurso para produzir a cena através do processo de "autoformação para a música em cena" realizado durante o processo de montagem do espetáculo Diz que sim.

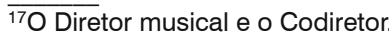

${ }^{18}$ Luana Leite
} 
Para estimular o jogo e a improvisação a fim de compor as canções foi preciso conhecer o caminho que o grupo estava propondo para a encenação. Havia uma proposta para a primeira cena, a partir da primeira frase do Grande Coro: "O mais importante de tudo é aprender a estar de acordo" musicada e cuja ação era inspirada em rituais xamânicos, em que o canto desta frase e sua cena já se estabeleciam neste sentido proposto. A partir, da melodia que as atrizes compuseram para essa primeira frase, coube ao formador de acordo com sua proposta de direção musical ajustar a partir do campo harmônico sugerido outras melodias para a métrica dos versos restantes, muitas vezes alterando os versos. Surgiram então novas linhas melódicas a partir daquilo que foi proposto. $\mathrm{O}$ trabalho em todo o texto foi basicamente o mesmo. Entretanto, percebeu-se que na medida em que a música entrava em cena a própria encenação era re-configurada favorecendo novas compreensões para a cena através da música.

Durante este processo, as atrizes participantes, aprenderam a formalizar a música e sua interpretação na qual aplicaram as possibilidades discursivas dessas linguagens como recurso gestual em cena. Assim precisou-se recriar a música que originalmente era de Kurt Weill ${ }^{19}$ e caracterizara uma pequena Ópera escolar que havia sido sua obra mais apresentada na Alemanha. Optou-se por assumir o texto de Brecht e abstrair-se da ideia de Ópera escolar, para incorporar as referências musicais das próprias atrizes e considerar um processo condizente com os recursos de produção. O trabalho permitiu, pelo princípio de desmusicalização da peça publicada a possibilidade de remusicalizá-lo. Ao, assim, assumir alguns trechos nos quais não há música, apenas texto falado a interpretação da direção cênica deu um caráter de Show musical, de certa forma, próximo à ideia realizada por Kurt Weill e Bertolt Brecht com os poemas musicados que geraram a cantata: "Mahagonny Singspiel", em que, ao que parece a ênfase não estava na encenação mas nas canções com interpretações que utilizavam de certos gestus para enfatizar o discurso e a narrativa. Do ponto de vista da própria teoria e contexto da Peça didática de Bertolt Brecht o texto podia ser praticado autonomamente, como dramaturgia, e estava aberto a novas músicas. Grosso modo, o processo de remusicalização desta Peça didática, seguiria alguns princípios do "modelo de ação brechtiano" (Handlungsmuster) que segundo Concílio (p. 20) diz respeito:

à proposta de utilização dessa dramaturgia como modelo norteador de experimentos, análises e improvisações, cujos usos recebem as intervenções dos integrantes envolvidos na criação e que compreendem, desde o início, o texto como mote de jogo, e não como algo definitivo a ser ilustrado na cena. (CONCÍLIO, 2016 p.20)

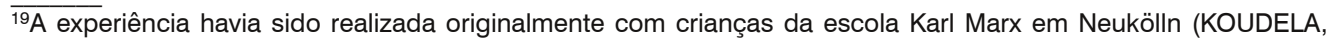
1991 p.56), estreou em 23 de Junho de 1930, no Instituto Central de Educação e Instrução em Berlim.

(EWEN, 1991). No contexto da música alemã as crianças conseguiam realizar, acompanhadas de uma orquestra amadora (EWEN, 1991, pp.227-228) experimentariam a criação de uma Ópera e nesse sentido havia o aprendizado também da estética operística a partir da sua revisão proposta por Brecht. Tecnicamente, a música incluía divisão de vozes, com sobreposição de melodias e uma instrumentação operística "normais" para a cultura musical alemã. Mesmo as vozes dos personagens principais requeriam um conhecimento de Bel canto, que por sua vez seriam realizadas por profissionais, ou semi-profissionais, que participariam precisão em relação às entradas e a regência. Mas o sentido da popularização da ópera para Brecht deveria produzir alterações em sua forma e em seu conteúdo. Portanto, na proposta que desenvolvemos não se trataria de uma remontagem que requeriria dos participantes que conhecessem a estrutura da música erudita no caso da montagem de Diz que sim, se optara pela referência das canções e músicas populares, mais próximas a do público e ao que se desenvolvera na parceria de Brecht com Weill para a Ópera de três vinténs.
} 
De acordo com a proposta sobre a estrutura do texto a experiência implicaria na necessidade de que elas cantassem em grupo e em solos aquilo que era previsto. No final da primeira parte as atrizes, conforme previsto pelo texto original, realizariam um discurso de posicionamento em relação a Viagem, feito a três vozes que se sobreporiam, em primeira e segunda pessoa conforme os personagens: Menino, cantando em primeira pessoa, Mãe e Professor em terceira:

\author{
Eu vou (ele vai) fazer \\ a perigosa caminhada. \\ E buscar remédios e instruções \\ Para a sua (a minha)doença, \\ Na cidade além das montanhas
}

Ainda que houvesse um coro composto por atrizes interpretando três mães, dois professores e um menino e cada uma delas trouxesse uma nuance para o significado da viagem que seria empreendida, precisava-se chegar a um "acordo" musical, uma afinação, uma harmonia, ou optar por uma dissonância. O acordo optou pela harmonia, ela foi solucionada através de um Cânone executado primeiro pelo Menino, a seguir pelas mães e depois pelos professores que se sobrepunham com uma distância de entrada dos versos em que conseguia-se ouvir a diferença nos textos, e ao mesmo tempo perceber o ressonar da mesma animada melodia, cantada com alegria pelo menino, com preocupação pelas mães e imparcialidade pelos professores mas cuja harmonia era alcançada pela estrutura do cânone.

Houve também a sugestão de se utilizar objetos como instrumentos sonoros melódicos ou de percussão: as garrafas que foram afinadas e sopradas compondo um acorde, o "cesto de lixo" percutido como um tambor. Estes objetos poderiam compor a cena e ao mesmo tempo possibilitar a criação de uma base harmônica e rítmica simples para vários momentos da peça. O domínio desses recursos dependeria também da implicação das atrizes em praticá-los sobre as músicas que foram criadas em improvisações proporcionando um arranjo mais complexo a instrumentação da cena que fora feita pelo músico (violino e piano) e pelo diretor de cena (palmas, acordeom e violão). No intuito de não aumentar as dificuldades optou-se por uma simplificação do uso desses objetos sonoros.

A intenção de ir à público com o trabalho resultante sobre o processo do Diz que sim foi determinado desde o princípio pelo Coletivo Baal. Se o processo formativo, por sua vez, não seria construído com um público, a direção tomada implicaria às participantes num estudo musical afim de apresentar o resultado a contento, o que a princípio era incerto. Porém, internamente o grupo assumiu o processo de aprendizagem (auto)formativo da música em cena para a Peça didática de modo que participaram ativamente do processo de criação da música e realizaram a música que ajudaram a compor.

Recorreu-se a vários procedimentos de musicalização para a cena, entre os quais o de reconhecer, o ritmo dos versos, a musicalidade possível no próprio texto traduzido, ou ainda, procurar sonoridades que enfatizassem a ideia presente no texto e adaptar a tradução em dinâmicas sonoras aproveitadas posteriormente para uma composição final que, na maior parte das vezes, ficaria a cargo da própria direção musical. Algumas das composições como a Canção Xamânica do Menino antes de ser jogado no penhasco e a Canção dos estudantes para a passagem estreita 
foram inteiramente composta pelas próprias atrizes ${ }^{20}$ já da forma que são apresentadas. No processo de composição com Brecht, Weill utilizava um procedimento semelhante ao que serviu as composições colaborativas. Weill finalizava as melodias que Brecht propunha assoviando, como foi o caso de algumas canções de Mahagonny:

Weill via o gestus como um elemento produzido pela música composta, sendo o assobio de Brecht apenas um esboço primitivo, ainda não "esclarecido". Ora, se o esboço assobiado por Brecht a partir de seus poemas, para Weill, não tem necessidade de tornar claro o gestus, é o compositor que vai, a partir do texto e deste esboço melódico (quando houver) construí-lo (TEIXEIRA JÚNIOR, 2014, p.58).

É importante lembrar que no caso da música original de Kurt Weill para Der Jasager era a de uma Ópera escolar (Schulloper), não havia texto sem música, a obra fora pensada para ser totalmente cantada ou no mínimo com trechos de recitativos. Essa música tinha sua intenção seu próprio Gestus, muitas vezes Kurt Weill, que compreendia que a música não servia apenas para o aprendizado musical, mas que haviam outras lições a serem aprendidas (CALICO, 2018 p.19) ${ }^{21}$. Ainda que a música de Weill tivesse alguns apelos populares da "música comunal" (Gemeinschaftsmusik). Segundo Teixeira Júnior:

Fazia-se música para rádio, música para filme, e, no aspecto pedagógico, "música para amadores", "música comunal" (Gemeinschaftsmusik), o que fez com que o festival de Baden-Baden atraísse "cantores de várias organizações juvenis" e criasse a peça didática, ou "ópera escolar" (Lehrstück) em que se pretendia que os intérpretes aprendessem enquanto cantavam" (WILLET, 1967, p.163165) (TEIXEIRA JÚNIOR, 2014, p.34)

Na melodia de Weill, especialmente para o Grande Coro, se tratava de uma ópera feita para ser realizada como tal, esse seria um desafio muito grande para o contexto da experiência de Diz que sim. Havia um aprendizado técnico, de linguagem, e outro do significado do uso desta linguagem como recurso estético. A encenação foi amadurecendo nestes dois sentidos.

O treinamento para canto foi feito, a partir da musicalidade que as atrizes traziam e no reconhecimento das vozes, seus timbres, tessituras, extensão que possibilitavam criar soluções cênicas como, por exemplo, foi solicitada a mudança de timbre para uma impostação de canto lírico para a segunda parte da música do Grande Coro, que inicia a parte 2 do texto. No texto se interferiu acrescentando repetições inexistentes no original (destacadas na citação em negrito), que, entre outras coisas, intencionavam reproduzir a imagem dos ecos em uma montanha. 0 gestual produzido pelo timbre lírico usado pelas atrizes enfatizado pela postura

\footnotetext{
${ }^{20}$ Thais Carli compôs a Canção Xamânica, e Gabriela Drehmer compôs a Canção dos estudantes na montagem de Diz que Sim.

${ }^{21}$ Calico citando Kurt Weill, escreve: Weill emphasized the musical lessons to be learned from the school opera He who Said Yes and balanced this with the importance of music as a tool for learning nonmusical lessons. (2008 p.19)
} 
física além de provocar um certo estranhamento, afetava a noção de alvorada que estava sendo narrada textualmente como algo bucólico e que na versão composta originalmente pelo grupo induzia a uma certa melancolia. Com o estranhamento produzido pelo surgimento da impostação do canto lírico abria-se novas possibilidades de interpretação também pelo Gestus das atrizes que aliadas à voz assumiam a postura de estar apoiando as mãos uma nas outras para sustentar o diafragma e utilizar a voz para cantar:

Na alvorada, ao pé da montanha, pé da montanha, pé da montanha. Ele não podia mais nem andar Seus pés cansados, seus pés cansados

Assim como no trabalho anterior com a peça "Badenbaden" (CONCíLIO,2016) o grupo havia experimentado que o processo formativo se tornasse um espetáculo, desta vez o objetivo era desde o princípio não ficar apenas no processo (auto)formativo das Peças didáticas. Estabeleceu-se a intenção de apresentar o resultado das experiências e de construir o trabalho como espetáculo. O processo (auto)formativo se compôs então do estudo necessário sobre a forma a ser consubstanciada como espetáculo musical. Isto exigiu treinamento e assimilação dos recursos musicais específicos que estavam sendo propostos e de que o discurso resultante foi se constituindo na forma final a partir dos ensaios - neles é que se encontrava a forma a ser transmitida para o público. Por outro lado, estabeleceu no processo (auto)formativo interno ao grupo-se uma relação com o expectador de forma diversa a aproximação projetada na teoria brechtiana e mesmo a desenvolvida em seus experimentos. O resultado espetacular para Brecht não era necessário, suas apresentações se deram como uma "espécie de demonstração" (KOUDELA, 1991 p.62). Por outro lado é importante reconhecer que mesmo com essa intenção as práticas originais realizadas por Brecht acabaram por atingir um resultado "finalizado" com os participantes levados a público como demonstrações das Peças didáticas, com gravações das apresentações e transmissões via rádio da Peça didática de Baden-Baden sobre o acordo, Lindberghflug e de Diz que sim.

No caso de Diz que sim, o objetivo de apresentação estabelecido pelo Coletivo Baal implicava na responsabilidade de finalização da forma em relação a uma linguagem que aprenderam no processo para construção de um espetáculo. Resulta que desta forma também se desenvolveu uma (auto)formação musical, ou seja, houve um aprendizado de maneira similar a desenvolvida nos Festivais de Baden-Baden em que as Peças didáticas surgiram. Do ponto de vista técnico e formativo o trabalho desenvolvido possibilitou o reconhecimento de um trabalho de canto coral para que as vozes afinassem e timbrassem. Também se estabeleceu uma autocompreensão que foi além da prática de composição e improvisação musical afim de que se pudesse elaborar o discurso textual através do uso dos recursos do canto, da melodia, dos arranjos e das harmonias. O grau de aprendizagem veio mesmo a permitir compreensão de outros aspectos da música que, desde o dodecafonismo, permitem assumir mesmo as dissonâncias na forma resultante do processo e torná-la reveladora de um discurso e do seu processo. 
Portanto, o próprio discurso cênico do espetáculo como um todo acabou alterado a partir dos processos de improviso utilizados para a criação musical, que mesmo nas versões já finalizadas consideravam as sugestões das atrizes para a interpretação e encenação. Muitas vezes, os resultados sugeriam outras nuances que foram apropriadas pela encenação como no caso da Canção de apresentação do professor, em que foi feito um dueto dos personagens do Professor e do Professor assistente. A interpretação aproveitava para revelar no personagem do Professor uma certa vaidade, uso e abuso do poder, que se reproduzia em relação ao Professor assistente e ao Menino - por exemplo: quando o Professor ao ser anunciado coloca seus pés sobre o Professor assistente que se deitou no chão e é recebido por uma mesura pelo Menino. Essas ações sobre a música e na música acabavam por produzir um estranhamento.

Estabeleceu-se um processo ao mesmo tempo formativo e (auto)formativo, em que o objeto de experiência era não apenas o texto de mas a música que fora criada. Num processo dialógico de criação foram sendo exercitadas: construções, desconstruções e reconstruções. O conhecimento da música, a prática do canto em coral e em solos, foram adquirindo novas formas no processo que reconhecia as referências autênticas da musicalidade que cada participante trazia para as experiências e que iam sendo incorporadas à prática.

Na Canção do professor ou mesmo na Canção do Grande Coro que abre a segunda parte algumas questões cênicas foram revistas, e que provocavam a revisão do texto a partir do sentido discursivo que a música trazia quando composta. Ou seja, nestes exemplos, o humor, a jocosidade, ironias eram utilizadas pelas intérpretes enfatizando o caráter ridículo da forma adotada pelo Canto lírico ou pelo bolero da canção do professor mostravam pelo conjunto gestual da música e da cena as contradições a serem observadas. Por exemplo, no caso da Canção do Grande Coro, que dá início a segunda parte, originalmente era chamada de Canção triste pela direção musical. Mas no processo havia uma quebra de andamento em que se mostrava o cansaço de quem havia subido uma montanha rapidamente e que vinha com a melancolia produzida pela "respiração" enfatizada pelas atrizes e pelo som do fole do Acordeom. Na retomada da melodia, sugeriu-se que as atrizes interpretassem utilizando o timbre de canto lírico o fazem numa postura de caricatura de cantoras líricas - e isso resultou em uma abertura à múltiplas interpretações. $\mathrm{Ou}$, ainda, no outro exemplo, enquanto o Professor assistente explica para o estudante os motivos dele não poder fazer a travessia enquanto canta o bolero, e conduz o Menino a uma dança em que este parece ser um marionete na condução afetada do Professor assistente. Desta forma se revela uma "máscara" de autoridade e ao mesmo tempo que ridiculariza a forma comum a alguns intérpretes populares do gênero bolero.

\section{Conclusões}

Brecht, ao elaborar sua reflexão e teorização sobre suas práticas, as tomou a partir do que havia vivenciado/experimentado nos contextos que se lhe apresentaram e que acabaram por determinar os caminhos da (auto)formação que desenvolvera para si e para outros. Desenvolveu propostas conscientes a respeito da forma, das intenções para estabelecer dispositivos, estratégias e modos de 
proceder possíveis para a realização de seus projetos musicais popularizando o acesso. Evidentemente, se trata de um autor e um encenador que estabeleceu uma perspectiva estética para a construção de grande parte de sua obra, mas ao colocála diante de processos colaborativos com outros autores/participantes considerou a dinâmica destes processos (com sujeitos e grupos sociais diversos) que devem ser considerados em sua singularidade em relação as outras experiências e grupos. $\mathrm{O}$ encontro com cada grupo, cada colaborador e cada ambiente interferiu na elaboração dos procedimentos das Peças didáticas criadas, cada qual com sua peculiaridade ainda que, também, contenham similaridades do mesmo modo que a publicação de seus textos possibilita outras releituras em outros contextos quase um século depois das montagens originais que foram concebidas com uma música e pensadas em uma determinada forma de experimento cênico.

Neste sentido, respondendo a pergunta: Como as intérpretes num processo (auto)formativo se apropriaram da música para estabelecer um discurso cênico a partir do texto Brechtiano e, também, em relação a própria posição de Brecht em relação ao texto? As intérpretes imergiram em um processo de autocompreensão (Selbstvesrtändigung) no sentido em que a vivência se tornou experiência apropriada em um processo de aprendizagem que envolvia a compreensão do discurso que queriam estabelecer. Não se tratava mais de um discurso pronto ou cópia de uma forma, mas de um estudo sobre o tema em que a forma se constituiu e utilizou para isso do recurso da música em cena. Trata-se de um discurso que se dá pela presença das atrizes no espetáculo que aprenderam a utilizar os recursos musicais, o que, por sua vez foi se firmando em processo dialético e não já como uma forma acabada ou doutrinária. Tratou-se de um processo em que cada construção se formou nas improvisações a partir de um discurso aberto à autocrítica e a novas possibilidades que poderiam se abrir. $O$ resultado não sendo fechado abre-se mesmo a criação de um outro espetáculo, como por exemplo a encenação da versão de Diz que não, ou ainda, em resposta ao próprio discurso estabelecido criticamente na criação de um Diz talvez.

Os recursos de reconhecimento e apropriação da linguagem musical serviram para ampliar as propostas interpretativas que iam sendo descobertas no processo. Assim as escolhas que foram feitas, podiam a qualquer momento ser rejeitadas na presença da cena, reinterpretadas e aplicadas a forma musical com as nuances de seu conteúdo crítico. Cada vez mais isso seria possível na medida em que permitia as atrizes o seu uso para compor seus Gestus, em sua própria apropriação da formação, em sua (auto)formação.

Cada processo pertence a seu tempo e lugar e traz as particularidades dos sujeitos envolvidos na produção, com as referências de vida e de contextos sociais, que traduzem através da arte uma complexidade de fatores que se apresentam para estabelecer sua "interpretação" e sua (auto)compreensão, com suas respectivas formas perceptíveis e experimentadas, em nosso caso, no uso da linguagem cênico-e musical, por exemplo, em nosso caso, apropriando-se de recursos da Música Popular Brasileira (MPB). com algumas de suas experiências com objetivos específicos e reativos às circunstâncias que o tempo exigia.

De qualquer forma, ainda que um grupo de formadores originais (dramaturgo, regentes e compositores) viesse a impor uma forma a ser seguida, na condução para o trabalho sem a interpretação de fato consciente, o "ensinamento" 
desejado não seria necessariamente apropriado pelos participantes da forma estabelecida. Trata-se de uma idealização muito mais do que uma prática real em que o sujeito nunca é completamente passivo, bem como nunca totalmente ativo e consciente. Pois, a orientação dos formadores do processo desconheceria a realidade específica de cada um dos sujeitos, que trás suas próprias referências e saberes, e que possivelmente sejam outras para a interpretação e construção de um sentido possível para sua obra de arte.

Ao pensarmos uma construção colaborativa (Ensemble), como é almejada pela teoria e prática brechtiana das Peças didáticas, pode haver sempre uma apropriação do processo e do discurso que vai se elaborando dialeticamente junto aos participantes - mesmo que aparentemente se contradiga - trata-se de algo móvel e circunstancial ligado à uma Pequena pedagogia que ainda é um recurso provisório em contraposição ao sistema. Mas, para uma retomada mais complexa com as $\mathrm{Pe}$ ças didáticas, com ou sem a música, formador e grupo de formação devem estar atentos a possibilidade de uma Grande Pedagogia. Em que se vislumbra a possibilidade de pertencer a uma experiência em que o teatro mudaria completamente de função, que não mais a de espetáculo mas de experimento social. Não se trata de um modelo a ser seguido e assimilado ipsis literis, mas de uma construção que depende do "acordo" dos participantes em relação ao contexto de produção.

Sua experiência, portanto, precisa ser realizada na prática coletiva: a práxis deve ser desenvolvida por cada um dos participantes, caso contrário, ele se torna mero expectador - que aprende, toma consciência de até onde chegou com seu fazer, mas que não esgota as possibilidades. Sem passar por uma inserção real no processo formativo, que é reflexivo e também prático para a construção da cena: o resultado do trabalho fica na vivência (Erlebnis). Mesmo na música, o participante que apenas repete a forma se torna apenas expectador pois não reconstrói a forma final, nem dialoga com o sentido da música sendo capaz de interferir no seu resultado; e quando interpreta, ainda que interaja com o conjunto da cena, que produza determinada resistência através de uma postura afastada do processo de negação da experiência, não toma consciência da práxis que é determinada pelo grupo que constrói a sua experiência interagindo com ela na função de encontrar a sua forma final, que de certa forma está sempre por vir e nunca está acabada por que depende da dinâmica em relação a plateia.

Portanto, para ser uma experiência brechtiana a prática exige dos participantes uma implicação com uma proposta (auto)formativa, em qualquer âmbito, afim de que se aprofunde na consciência do uso dos recursos da linguagem cênica e musical para apresentar um discurso cênico coerente em relação a sua participação na vida social e política, determinada pelo acordo comum do grupo em relação àquilo que foi definido dialeticamente no processo de criação. Ou para finalizar, reafirmando uma grande citação sobre as propostas pedagógicas e formativas retiradas de anotações de Brecht cujos fragmentos estão grafados da seguinte forma, sem distinguir maiúsculas e minúsculas na obra de Ingrid Koudela:

para evitar um novo equívoco: a questão não deve ser se no interesse do ensino teria sido melhor esconder a intenção de ensinar, muitas pessoas, entre elas as mais "avançadas", exigem de fato que o ensinamento seja oculto, querem ser ensinadas de uma forma 
forma subterrânea, refinada, intrigante, detestam o dedo em riste, e querem conhecer através da flor. já do ponte de vista social, o doutrinário é tido como deselegante. eu seria injusto com meus amigos que querem conhecer através da flor (de forma graciosa), se não considerasse seriamente suas propostas e ponderações. eles acreditam sem levar em conta os efeitos do choque social - antes na eficácia pedagógica de uma forma de ensino de tipo concreto, que permanece no puramente contemplativo e resiste à abstração. temem o coque social. é relativamente fácil mostrar-lhes que esse choque é determinado socialmente e caracteriza apenas uma camada social que entende por aprendizagem algo muito bem determinado - a apropriação da cultura, a compra de uma mercadoria - e percebe o estudo como algo que os torna aptos para a carreira. portanto, uma camada que para nós não pode ser ensinada e é excluída. eles, como nós, entendem a aprendizagem como um processo, sendo que se trata de um processo vitalício e constante de adequação às circunstâncias. só o concluem ao morrer, não se ressentem quando ensinados. entendem não apenas que devem ser ensinados pelas circunstâncias como também pelos homens, que também podem ser ensinados. pois é justamente esse tipo de circunstâncias, que de outro modo seriam fenômenos fetichistas do destino, o que as torna passíveis de serem manipuladas. mas eles querem conhecer através do caminho da experiência - da experiência sensível, da vivência. eles querem o envolvimento, não querem ser confrontados, diante deles é necessário defender o conceito da peça didática, da dramaturgia pedagógica. ela é defendida, ao ser aprofundada.

portanto, agora não se coloca mais a questão: deve-se ensinar? agora a questão é "como se deve ensinar e aprender?" (Equívocos sobre a Peça didática, Bertolt Brecht apud KOUDELA, 1991 p.23) [grafia conforme original]

No processo experiencial observa-se que aquele que propõe a formação também no aspecto musical deve ter uma percepção atenta para a apropriação do material criativo que surge para que se torne algo coerente com o discurso desejado pelo coletivo e assim favorecer realmente a ideia brechtiana em relação ao papel da música em cena. De modo que quem propõe a formação se forma também na elaboração da experiência que desenvolve com as Peças didáticas com que se implicou.

\section{Referências}

BENJAMIN, Walter. Obras escolhidas V. 1. São Paulo: Editora Brasiliense, 1987.

Tentativas sobre Brecht. Madrid: Taurus Ediciones, 1987a.

BRECHT, Bertolt. Obras Completas, V. 3. São Paulo: Editora Paz e Terra, 1992

Estudos sobre Teatro. Rio de Janeiro: Nova Fronteira, 1978. 
Teatro dialético, Rio de Janeiro: Editora Civilização Brasileira, 1967

CALICO, Joy. Brecht at the opera, University of California Press, 2008.

CONCÍLIO, Vicente. BadenBaden - Modelo de ação e encenação no processo com a Peça didática de Bertolt Brecht. São Paulo: Paço Editorial, 2016.

EWEN, Fredric. Brecht sua vida, sua arte, seu tempo. São Paulo: Editora Globo

GATTI, Luciano. Benjamin e Brecht: a pedagogia do Gesto. In.: Cadernos de Filosofia alemã, n.o 12, 2006, pp. 51-78.

KOUDELA, Ingrid. Brecht: Um jogo de aprendizagem. São Paulo: Editora Perspectiva, 1991.

STEINWEG, Reiner. Das Lehrstück. Stuttgart: Metzler, 1976.

TEIXEIRA JÚNIOR, Geraldo Martins - Dramaturgia, gestus e música. Estudos sobre a colaboração de Bertolt Brecht, Kurt Weill e Hanns Eisler, entre 1927 e 1932 (Tese) Universidade de Brasilia, UnB, 2014

Referências audiovisuais:

<http://www.medienkunstnetz.de/works/bertold-brecht/audio/1/(...)>

<http://www.sz-photo.de/?60044309618120829140>

Recebido em 23/06/2017 Aprovado em 09/07/2017 